\title{
ANALYSIS OF AROMA VOLATILES GENERATED DURING THE EXTRUSION OF MAIZE FLOUR USING SOLID PHASE MICRO - EXTRACTION (SPME)
}

\author{
( Received: 6.5. 2008 )
}

\author{
By \\ A. Farouk \\ Flavor \& Aromatic Chemistry Department, National Research Center, Dokki, Giza, Egypt.
}

\begin{abstract}
Volatile components in extruded maize flour at $140^{\circ} \mathrm{C}$ were extracted by Solid Phase Micro Extraction (SPME), identified and evaluated by GC - MS. More than 90 compounds were successfully detected. Among the flavor active volatiles, pyrazines were the most prominent class of compounds, especially the alkyl substituted derivatives, followed by furans. Few pyrroles and sulfur - compounds were also identified. The above classes are highly contributed to the overall flavor, in spite of their relatively low amounts which may be due to the low extrusion temperature. Aldehydes, fatty acids, ketones, hydrocarbons and other aliphatic derivatives contributed only a little to the resulting flavor in contrast to their amounts among the identified volatiles. Maillard reactions as well as lipid degradation are the main reasons for the formation of these volatiles. The browning reaction is only moderate, the increase of $\mathrm{a}^{*}$ (redness -positive- to greenness -negative) and $\mathrm{b}^{*}$ (yellowness - positive- to blueness negative) corresponds to the increase in redness and yellowness, respectively, which occurs in the beginning of non-enzymatic browning. Sensory characteristics of the extruded maize flour could be easily correlated with the identified compounds.
\end{abstract}

Key words: aroma volatiles, color, extrusion, flavor, maize flour, sensory, SPME.

\section{INTRODUCTION}

The extrusion cooking has become a favorite alternative for baking, particularly for the technological processing of cereals and starchy foods into a variety of food products (Huber, 1991) The extrusion conditions reduced the requirements for energy as well as the moisture content in comparison to baking technique which may lead to damage by microorganisms during storage. During extrusion, raw materials exposed to high temperature, pressure and shear force to mix and cause chemical changes which constitute cooking.

These chemical changes, among many others, involve the production of flavors which give the final product its characteristics. These flavor compounds may be originated from a number of compounds in the starting material and through a number of different reactions including lipid oxidation, breakdown of carotenoids, deamidation of glutamine and asparagines and the formation of Maillard reaction products (Riha and Ho, 1998). Analysis of flavor volatile compounds produced during extrusion of ground malt (Fors and Eriksson, 1986), potato flakes (Maga and Sizer, 1979) and semolina (Farouk et al., 2000; Farouk et al., 2001), showed the effects of different extrusion conditions on the yield of pyrazines.

Pyrazines which are one of the classes responsible for the toasted and nutty extrudate flavor, may be originated from the proteins and carbohydrates found in flours. During extrusion of oat flour, compounds such as 2,4-decadienal and 2,4-nonadienal were detected due to lipid degradation as well as vanillin which may be due to phenol content of the flour (Guth and Grosch, 1993).

One of the most important raw materials for extrusion cooking is corn meal, which is transformed into extrudates of interesting flavor character (Chen et al., 1991). The main advantage of corn processing is time, energy and cost saving. The volatiles produced from an extruded corn - based model system has been studied by Ho et al . (1989) using single screw extruder at $120^{\circ} \mathrm{C}-165^{\circ} \mathrm{C}$. The extruded samples were ground and extracted with diethyl ether, the volatiles were analyzed by Gas Chromatography (GC) and Gas Chromatography / Mass Spectrometry (GC / MS). Another study on flavor production during corn flour extrusion was performed using twin - screw extruder at $178^{\circ} \mathrm{C}$ (Nair et al.,1994).Volatiles were collected 
using cold-trap, analyzed by GC / MS, but surprisingly without any kind of quantification. A drawback of extruded products is their weaker aroma and flavor intensity than that of traditional bakery products (Pokorny et al., 2002). Recent developments in the methods of isolation and measurement of volatiles should be exploitive, especially supercritical fluid and SPME which have not yet been fully evaluated for cereals. However, SPME is nowadays accepted as a simple and powerful tool for solving many analytical problems (Pawliszyn, 1997).

The present study aimed to characterize the volatile aroma compounds using SPME in the extrusion cooking of maize flour at standard industrial conditions and normal moisture content, as well as the sensory evaluation of the final product.

\section{MATERIALS AND METHODS}

\subsection{Source of maize flour}

Maize flour was obtained from Azteca Milling L. B., (Edinburgh, Texas, USA), Type CHIP DELIGHT \#6 YELLOW. It contained $12.0 \%$ moisture, $1.0 \%$ ash, $8.2 \%$ protein and $3.5 \%$ fat

\subsection{Extrusion process}

The material $(5 \mathrm{Kg}$.) was thoroughly sieved and then fed to the extruder (single - screw collet VUMPP-83, CR; screw type: 3-way; distance between flights: $36 \mathrm{~mm}$; screw rotation: $5.85 \mathrm{~Hz}$; dosing: 1.923; feed rate: only in the feed zone, defined by dosing; residence time: $30 \mathrm{~s}$; the maximum extrusion temperature: $140^{\circ} \mathrm{C}$; dosing: $40 \mathrm{Kg} / \mathrm{h}$; shaping dies: diameter of $12 \mathrm{~mm}$; distance dies: diameter of $88 \mathrm{~mm}$; die temperature: $110^{\circ} \mathrm{C}$ ). The extruded samples were immediately crushed and stored at room temperature in ground glass bottles filled up to the neck.

\subsection{Extraction of volatiles}

The SPME procedure was used (Farouk et al., 2001). A Carboxen ${ }^{\mathrm{TM}} /$ Polydimethylsiloxane (PDMS) $75 \mu \mathrm{m}$ fibre for manual holder was produced by Supelco (Bellefonte, CA, USA). The extraction time was 1 Hour at $85^{\circ} \mathrm{C}$, and the desorption time was $2 \mathrm{~min}$ at $220^{\circ} \mathrm{C}$. The fibre was then cleaned for $30 \mathrm{~min}$ at $220^{\circ} \mathrm{C}$ before extracting the next sample. The procedure is affected by the extraction conditions due to which, these were carefully controlled. The results apply, nevertheless, solely to the sample analyzed, and to the solid phase used for extraction.

\subsection{Gas Chromatography/Mass Spectrometric analysis (GC / MS)}

The obtained volatiles were analyzed using GC-MS apparatus. Separation was performed on Thermo gas chromatograph (Walnut creek, California, USA) equipped with Finnigan mat SSQ 7000 mass spectrometer and a $60 \mathrm{~m} \mathrm{x}$ $0.32 \mathrm{~mm}$ DB-wax capillary column (J\&W, USA). The column temperature was programmed from $50^{\circ} \mathrm{C}$ (isothermal for $2 \mathrm{~min}$.) to $220^{\circ} \mathrm{C}$ at a rate of $2{ }^{\circ} \mathrm{C} / \mathrm{min}$ with $30 \mathrm{~min}$. isothermal hold. The injector temperature was $220^{\circ} \mathrm{C}$ and the transition line temperature was $220^{\circ} \mathrm{C}$. The carrier gas was helium and the column pressure head was $10-15 \mathrm{psi}$. The mass spectrometer had a scan range from $\mathrm{m} / \mathrm{z} 33$ to $\mathrm{m} / \mathrm{z} 300$. Ionization energy was set at $70 \mathrm{eV}$. Identification of compounds was based on the comparison with the MS computer library (NIST and Wiley software package, ThermoFinnigan) and published spectra. A linear retention index was calculated for each compound using the retention times of a homologous series of C6 - C26 nalkanes.

\subsection{Color evaluation}

The extrudate sample was finely ground for 30s in a Moulinex processor (Moulinex, France). A CCD fiber optic spectrophotometer S 200 (Ocean Optic. Ltd., FL, USA) was used for measuring the reflected light. A standard light source D65 was used; the reflexion assembly probe consisted of 7 fibers in a ferrule. The results were processed by the software Spectrawin version 3.1. The following parameters were measured: $\mathrm{L}^{*}$-expressed the lightness (in \%); the $\mathrm{a}^{*}$ value - redness (positive) to greenness (negative); $b^{*}$ value - the yellowness (positive) to blueness (negative); the hue angle $\mathrm{h}^{*}$ is defined as $\tan ^{-1} \mathrm{~b}^{*} / \mathrm{a}^{*}$; the

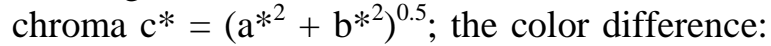
$\Delta \mathrm{E}=\left(\Delta \mathrm{a}^{*^{2}}+\Delta \mathrm{b}^{* 2}+\Delta \mathrm{L}^{* 2}\right)^{0.5}$.

\subsection{Sensory analysis}

The sensory analysis was carried out under the conditions specified by the international standards (ISO); general guidelines after ISO 6658-1985; unstructured graphical scales (ISO 4121.2-1988) were presented as straight lines $70 \mathrm{~mm}$ long, provided with descriptors on either ends (intensity of brown coloration: $0 \mathrm{~mm}=$ very light, $70 \mathrm{~mm}=$ very dark; pleasantness of odor: 0 $\mathrm{mm}=$ very unpleasant, $70 \mathrm{~mm}=$ very pleasant; odor intensity: $0 \mathrm{~mm}=$ imperceptible, 70 $\mathrm{mm}=$ very strong; texture (assessed by pressing the sample between fingers): $0 \mathrm{~mm}=$ greasy, 70 $\mathrm{mm}=$ fragile). The sensory profile is based on free choice profiling, and the following descriptors were retained out of 32 collected descriptors (Farouk et al., 2000; Farouk et al., 2001): $1=$ roasted, bread crust, roasted peanuts, 
ginger bread; $2=$ burnt, caramel, bitter; $3=$ woody, peel, rubbery; 4=after dough, floury, bread crumb; 5= spicy, sulphur, after onion, garlic; $6=$ sharp, pungent, penetrating; $7=$ fatty, oily, buttery; $8=$ earthy, musty, after earthy, moldy, after sweat, wet dog; 9= malty, cocoa powder, sweet; $10=$ solvents, synthetics, chemicals; $11=$ others. The profile evaluation of the descriptors range from $0 \mathrm{~mm}=$ absent, 70 $\mathrm{mm}=$ very strong. The colour intensity and the colour hue were assessed under standard light source $\mathrm{C}$ (CIE, corresponding to the spectrum of sun surface ). Odour profiles are tested by sniffing from ground wide - neck $500 \mathrm{ml}$. glass bottles.

\section{RESULTS AND DISCUSSION}

The identified compounds of the volatile fraction are shown in Table (1) and Figure (1). Ninety-three compounds were recorded, including 19 pyrazines, 10 furans, 9 aliphatic alcohols, 9 aliphatic carboxylic acids, 7 aliphatic aldehydes, 6 pyrroles, 6 sulfur - containing compounds, 6 aliphatic hydrocarbons, 5 aliphatic ketones and 1 pyridine. The quantitative distribution of different classes of compounds showed that, aliphatic aldehydes are predominant $(20.85 \%)$, followed by pyrazines $(17.98 \%)$ and aliphatic carboxylic acids (16.80\%), while the sulfur-containing is the least detected group with $0.90 \%$.

Only about 80 compounds were identified by Bredie et al. (1998 a \& b) in eight maize extrudates treated at different conditions, among them 40 compounds at $120^{\circ} \mathrm{C}$ and $150^{\circ} \mathrm{C}$ with different moisture content. While a smaller number could be detected by Ho et al. (1989) at $120{ }^{\circ} \mathrm{C}$. In another interesting study, Nair et al. (1994) recovered less than 50 compounds from extrudate and detected about 70 volatiles released at the die, but unfortunately, they did not quantify them. In the discussion concerning the composition of volatiles, it should be made clear that, the results depend on the extraction method. In the case of the SPME method, it depends on properties of the film on the fibre surfaces, which is carboxen in the present study.

Pyrazines are one of the most important classes identified in the extrudate. The derivatives of pyrazines detected, were common to other extruded cereals and to many heat processed foods and model systems (Maga, 1992). Methyl pyrazine, dimethyl pyrazines and ethyl dimethyl pyrazines were previously reported in other studies (Ho et al., 1989; Bredie et al., 1998 a \& b), however, most of the rest pyrazines detected in the extrudate, were not identified before under the same extrusion temperature, including derivatives with higher concentrations e.g. trimethyl pyrazine (1.29\%) and vinylmethyl pyrazines (1.29\%). Generally, pyrazines are formed in the reaction of an aminogroup with carbonyl group during Maillard browning reaction (Hwang et al., 1994 a \& b). Proteins, peptides and amino acids, present as natural components in maize flour, were obviously sufficient for the pyrazine formation. The amount of ammonia, necessary for the pyrazine formation can be liberated not only by the cleavage of the peptide bond, but also by deamidation of glutamine and asparagines bound in proteins (Zhang, 1994). Additionally, Maillard reaction may occur even if no reducing sugar is added to the feed, since starch and fiber fragments can react (Camire, 1998). Most of the pyrazines identified in the extrudate, consisted of methyl- and methylethyl substituted derivatives which provide a roasted and toasted flavor note (Maga, 1992). They were reported among pyrazines from crust of white American bread (Sizer et al., 1975). However, vinyl and acetyl derivatives here identified are in agreement with those formed in extruded malt, which also contain reducing sugars (Fors and Eriksson, 1986).

Ten furans were identified in the extrudate, only pentyl furan, furfural and furanmethanol were reported before, while the rest are not. Furans are oxygen-containing heterocycles that provide a sweet, or caramel - like aroma and may be formed from pyrolysis of sugars (Fors, 1983). During extrusion, the branched structure of amylopectin branches is susceptible to shear. Both amylose and amylopectin molecules may decrease in molecular weight. Politz et al. (1994) studied relative molecular weight distribution in extruded corn flour containing $60 \%$ amylopectin. Large amylopectin molecules were more likely to degrade. This molecular degradation may be exploited to produce dextrins and monosaccharides (glucose) which may be the main furan source.

The two thiophenes identified in the extrudate, namely 2-hexyl thiophene $(0.14 \%)$ and 2-thiophene carboxaldehyde $(0.01 \%)$ are not reported before during extrusion at the same conditions. Thiophenes are sulfur - containing compounds which have been previously reported in cooked meat and are generally responsible for a mild sulfurous odor (Shibamoto, 1980). Shibamoto (1977) concluded that, thiophenes were formed from the reaction of a sugar or carbohydrate with hydrogen sulfide or an amino acid. 2-Formyl thiophene may be produced 
Table (1): Volatile compounds identified in the extruded maize flour.

\begin{tabular}{|c|c|c|c|c|}
\hline No. & Compound & Rt. & RI & Area \% \\
\hline 1 & 3-Methyl butanal & 6.470 & 907 & 0.85 \\
\hline 2 & Decane & 6.729 & 1000 & 1.24 \\
\hline 3 & Benzene, 2-methylpropyl- & 7.771 & 1067 & 1.19 \\
\hline 4 & Hexanal & 8.763 & 1096 & 17.34 \\
\hline 5 & p-Xylene & 10.381 & 1133 & 0.45 \\
\hline 6 & 1-Butanol & 10.606 & 1138 & 0.33 \\
\hline 7 & Heptanal & 11.840 & 1176 & 0.62 \\
\hline 8 & Decane, 2,4(3,6)-dimethyl- & 11.965 & 1178 & 1.28 \\
\hline 9 & d-Limonene & 12.107 & 1181 & 3.01 \\
\hline 10 & Undecane, 4-methyl- & 12.290 & 1184 & 6.30 \\
\hline 11 & Pyrazine & 12.807 & 1194 & 0.11 \\
\hline 12 & Furan, 2-pentyl- & 13.516 & 1217 & 1.17 \\
\hline 13 & 2-Methylthiazole & 13.691 & 1240 & 0.03 \\
\hline 14 & 1-Pentanol & 13.966 & 1242 & 1.82 \\
\hline 15 & Thiazole & 14.091 & 1249 & 0.04 \\
\hline 16 & Pyrazine, 2-methyl- & 14.608 & 1257 & 2.28 \\
\hline 17 & Benzene, 1-methyl-4-(1-methylethyl)- & 14.842 & 1261 & 0.12 \\
\hline 18 & Benzene, 1,3,5-trimethyl- & 15.250 & 1283 & 0.18 \\
\hline 19 & 2-Pentanol, 4-methyl- & 15.400 & 1286 & 0.21 \\
\hline 20 & Tridecane & 15.684 & 1300 & 5.96 \\
\hline 21 & Acetic acid, methyl ester & 15.942 & 1302 & 0.96 \\
\hline 22 & Pyrazine, 2,5-dimethyl- & 16.526 & 1315 & 4.27 \\
\hline 23 & Pyrazine, 2,6-dimethyl- & 16.743 & 1322 & 5.32 \\
\hline 24 & Pyrazine, ethyl- & 16.968 & 1325 & 0.17 \\
\hline 25 & Pyrazine, 2,3-dimethyl- & 17.376 & 1336 & 0.13 \\
\hline 26 & 1-Hexanol & 17.526 & 1354 & 0.51 \\
\hline 27 & 2-Isopropyl-5-methyl-hex-2-enal & 17.952 & 1362 & 1.11 \\
\hline 28 & Pyrazine, 2-ethyl-6-methyl- & 18.735 & 1378 & 0.29 \\
\hline 29 & Dimethyltrisulfide & 18.769 & 1379 & 0.63 \\
\hline 30 & Pyrazine, 2-ethyl-5-methyl- & 18.952 & 1384 & 0.66 \\
\hline 31 & Pyrazine, trimethyl- & 19.336 & 1397 & 1.29 \\
\hline 32 & Pyrazine, 2-ethyl-3-methyl- & 19.419 & 1403 & 0.41 \\
\hline 33 & 3-Octen-2-one & 19.586 & 1406 & 0.35 \\
\hline 34 & 1,3-Hexadiene, 3-ethyl-4-methyl- & 19.953 & 1412 & 0.53 \\
\hline 35 & Pyrazine, 2-vinyl- & 20.628 & 1422 & 0.10 \\
\hline 36 & Benzene, 1-ethenyl-3(4)-ethyl- & 20.661 & 1425 & 0.47 \\
\hline 37 & Pyrazine, 3-ethyl-2,5-dimethyl- & 20.761 & 1435 & 1.16 \\
\hline 38 & 7-Octen-4-ol & 20.936 & 1438 & 0.82 \\
\hline 39 & 1-Hexanol, 3(5)-methyl- & 21.095 & 1442 & 0.29 \\
\hline 40 & Acetic acid & 21.337 & 1448 & 0.02 \\
\hline 41 & 2-Furfural & 21.662 & 1461 & 0.13 \\
\hline 42 & 1-Hexanol, 2-ethyl- & 22.295 & 1471 & 0.37 \\
\hline 43 & Pyrazine, 2-vinyl-6-methyl- & 22.370 & 1473 & 0.87 \\
\hline 44 & Pyrazine, 2-vinyl-5-methyl- & 22.587 & 1476 & 0.42 \\
\hline 45 & Decanal & 22.704 & 1484 & 0.36 \\
\hline 46 & Ethanone, 1-(2-furanyl)- & 23.029 & 1487 & 0.19 \\
\hline 47 & 3,5-Octadien-2-one & 23.429 & 1498 & 0.18 \\
\hline 48 & Benzaldehyde & 23.679 & 1505 & 3.86 \\
\hline
\end{tabular}


Cont., Table (1):Volatile compounds identified in the extruded maize flour.

\begin{tabular}{|c|c|c|c|c|}
\hline 49 & 2-Nonenal & 23.963 & 1510 & 0.43 \\
\hline 50 & 1-Octanol & 24.538 & 1530 & 0.58 \\
\hline 51 & Thiophene, 2-hexyl- & 24.863 & 1544 & 0.14 \\
\hline 52 & 3,5-Octadien-2-one & 25.113 & 1555 & 0.21 \\
\hline 53 & 2-Furancarboxaldehyde, 5-methyl- & 25.297 & 1562 & 0.06 \\
\hline 54 & Pentadecane, 2-methyl- & 25.847 & 1575 & 0.22 \\
\hline 55 & Ethanone, 1-(2-pyridinyl)- & 26.239 & 1585 & 0.16 \\
\hline 56 & 2-Octen-1-ol & 26.431 & 1592 & 0.05 \\
\hline 57 & 2-Methyl-3-propylpyrazine & 26.689 & 1601 & 0.06 \\
\hline 58 & Acetylpyrazine & 26.989 & 1611 & 0.43 \\
\hline 59 & Butyrlactone & 27.198 & 1624 & 2.30 \\
\hline 60 & 2-Acetylthiazole & 27.665 & 1641 & 0.05 \\
\hline 61 & Acetophenone & 27.806 & 1646 & 0.76 \\
\hline 62 & 2-Furanmethanol & 27.956 & 1651 & 0.12 \\
\hline 63 & 6,7-Dodecanedione & 28.031 & 1654 & 0.54 \\
\hline 64 & 2-Pyrrolidone, 1-methyl- & 28.306 & 1666 & 0.06 \\
\hline 65 & 1-(5-Methyl-2-pyrazinyl)-1-ethanone & 28.748 & 1675 & 0.17 \\
\hline 66 & 1-(6-Methyl-2-pyrazinyl)-1-ethanone & 29.040 & 1684 & 0.19 \\
\hline 67 & 3-Thiophenecarboxaldehyde & 29.198 & 1687 & 0.01 \\
\hline 68 & 2-Methyldihydrocyclopentapyrazine & 29.599 & 1707 & 0.08 \\
\hline 69 & Pentanoic acid & 30.482 & 1736 & 0.60 \\
\hline 70 & Pentanoic acid, 4-methyl- & 32.433 & 1756 & 0.14 \\
\hline 71 & 2,4-Decadienal & 32.575 & 1758 & 0.14 \\
\hline 72 & 2-Cyclopenten-1-one, 2-hydroxy-3-methyl- & 33.033 & 1793 & 1.32 \\
\hline 73 & Hexanoic acid & 33.600 & 1847 & 9.19 \\
\hline 74 & 1-(5-Methyl-2-furanyl)-1,2-propandione & 34.067 & 1852 & 0.01 \\
\hline 75 & Benzyl alcohol & 34.492 & 1873 & 0.18 \\
\hline 76 & Butylatedhydroxytoluene & 35.468 & 1922 & 0.32 \\
\hline 77 & 2(3H)-furanone, 5-butyldihydro- & 35.743 & 1936 & 0.10 \\
\hline 78 & Hexanoic acid, 2-ethyl- & 36.493 & 1947 & 0.26 \\
\hline 79 & Heptanoic acid & 36.627 & 1950 & 0.82 \\
\hline 80 & Maltol & 36.927 & 1954 & 0.16 \\
\hline 81 & Ethanone, 1-(1H-pyrrol-2-yl)- & 37.160 & 1956 & 0.24 \\
\hline 82 & Phenol & 38.127 & 1997 & 0.61 \\
\hline 83 & 1H-Pyrrole-2-carboxaldehyde & 38.677 & 2008 & 0.11 \\
\hline 84 & 2-Pyrrolidinone & 38.811 & 2010 & 0.27 \\
\hline 85 & Benzofuran, 7(2)-methyl- & 39.136 & 2014 & 0.96 \\
\hline 86 & Octanoic acid & 39.469 & 2019 & 4.16 \\
\hline 87 & 1-Pyrrolidinecarboxaldehyde & 41.242 & 2099 & 0.07 \\
\hline 88 & Nonanoic acid & 42.209 & 2144 & 0.83 \\
\hline 89 & 4-Hydroxy-2-methylacetophenone & 43.068 & 2183 & 0.24 \\
\hline 90 & Decanoic acid & 44.810 & 2262 & 0.57 \\
\hline 91 & 4H-Pyran-4-one, 2,3-dihydro-3,5-dihydroxy-6-methyl- & 45.327 & 2286 & 1.36 \\
\hline 92 & Benzofuran, 2,3-dihydro- & 48.137 & 2388 & 0.29 \\
\hline 93 & Indole & 49.938 & 2454 & 0.03 \\
\hline
\end{tabular}




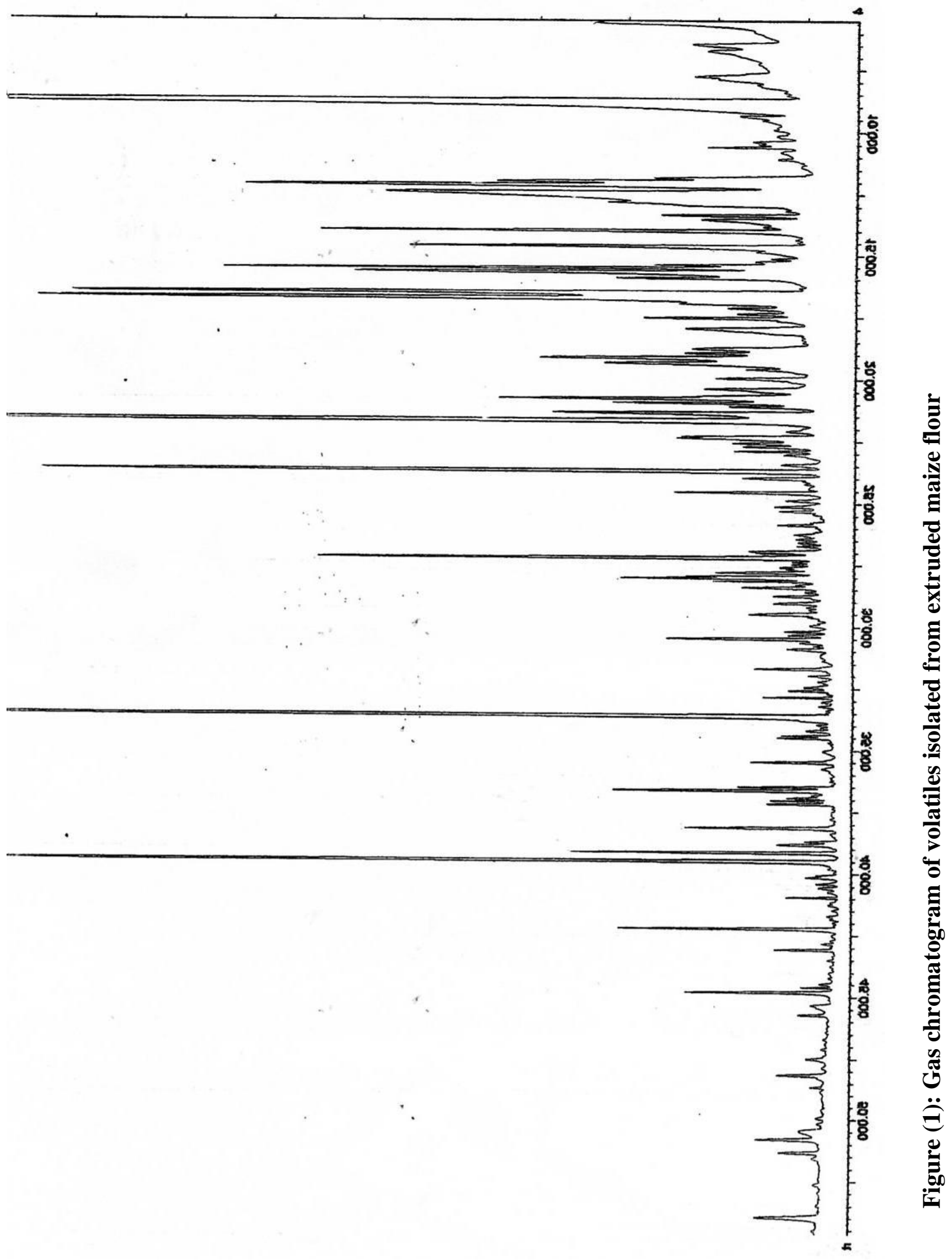


from the reaction of furfural, hydrogen sulfide and ammonia during extrusion, while long chain alkyl thiophenes may be formed by the reaction of hydrogen sulfide or ammonia with alkadienals (Farmer et al., 1989).

The flavor characteristics of thiazoles have been previously reviewed by Maga (1992). Thiazoles have a meaty flavor and are used extensively in producing meat flavorings. Thiazole, methyl thiazole and acetyl thiazole were tentatively identified in the extrudate. The mechanistic pathways for the production of thiazoles depend on thiamine decomposition during extrusion (Ho et al., 1989) or thermal degradation of cysteine (Shu et al., 1985; Zhang et al., 1988), however, 2-acetylthiazole, which may be formed from reaction of the Strecker aldehyde of cysteine with pyruvaldehyde (Mulders, 1973). In agreement with Bredie et al. (1998 a \& b), dimethyltrisulfide is the aliphatic sulfur-containing compound identified in the extrudate at this extrusion temperature, regardless to moisture content. This polysulfide has been reported in the extrudate of yeast extract (Izzo and Ho, 1991) and high - gluten wheat flour (Hwang et al., 1994a\&b). The possible precursors for this polysulfide are hydrogen sulfide and methanethiol which is a degraded product from sulfur-containing amino acid (cysteine, methionine, S-methyl methionine) (Madruga and Mottram, 1998).

Only a few pyrroles have previously been identified in extruded cereals, mainly in maize (Nair et al., 1994). 2-Acetylpyrroline and acetyl pyridines were reported before in both popcorn (Buttery et al., 1997) and extruded maize (Bredie et al., 1998 a \& b), but in addition to these compounds, another four pyrroles were identified in the extrudate. It was suggested that, alkylpyrroles formed via a pyrolytic degradation of the amino acids alone, whereas acyl or aldehydic pyrroles required the presence of a sugar source (Mottram and Whitfield, 1995; Baltes and Bochmann, 1987; Shieberle, 1991) and Buttery et al.., 997). Buttery and Ling, 1995 have shown that acetyl pyrroles and pyridines are all important to popcorn aroma, the main odor description used by a sensory panel evaluating 2-acetyl-1-pyrroline was "pop-corn".

Short-chain aldehydes, ketones and various dicarbonylic precursors increased by decomposition of carbohydrates e.g. acetic acid, methyl ester, while others may be formed as Strecker degradation of amino acids e.g. 3methyl butanal (Farouk et al., 2001). The content of butyrolactone substantially increased too, while maltol is produced by thermolysis of Amadori compounds (Yaylayan et al., 1992). The origin of most long - chain aliphatic aldehydes, alcohols as well as aliphatic hydrocarbons is the oxidative and / or thermal degradation of lipids (Grosch, 1982). Alkanals detected among the volatiles could not have much pronounced influence on the resulting flavor as they were high molecular - weight compounds (6 - 12 C-atoms). The Maillard reactants had various effects on the products of lipid oxidation; the greatest one was on amounts

Table (2): Color parameters of extruded maize flour.

\begin{tabular}{|c|c|c|c|c|c|c|}
\hline Sample & $\mathbf{L}^{*}$ & $\mathbf{a}^{*}$ & $\mathbf{b}^{*}$ & $\mathbf{h}^{*}$ & $\mathbf{c}^{*}$ & $\mathbf{\Delta E}$ \\
\hline White blank & 50.68 & -9.26 & 9.21 & 135.68 & 12.72 & ---- \\
\hline Black blank & 50.86 & 1.6 & 25.94 & 84.42 & 28.03 & --- \\
\hline Extruded maize flour & 50.46 & 15.68 & 76.16 & 78.58 & 77.73 & 71.44 \\
\hline
\end{tabular}

Table (3): Sensory evaluation of extruded maize flour.

\begin{tabular}{|l|c|}
\hline \multicolumn{1}{|c|}{ Property } & Extruded maize flour \\
\hline Intensity of browning & 6.3 \\
\hline Pleasantness of odor & 41.9 \\
\hline Intensity of odor & 25.3 \\
\hline Texture (between fingers) & 40.8 \\
\hline Ginger bread, roast, bread crust, roasted groundnuts & 23.0 \\
\hline Burnt, caramel, bitter & 14.1 \\
\hline Woody, peel, rubbery & 12.0 \\
\hline After dough, flour, bread crumb & 33.2 \\
\hline Spicy, sulphur, after onion, garlic & 22.8 \\
\hline Penetrating, sharp, pungent & 9.8 \\
\hline Fatty, oily, buttery & 19.4 \\
\hline Earthy, musty, after earthy, mouldy, after sweet, wet dog & 11.9 \\
\hline Malty, cocoa powder, sweet & 25.0 \\
\hline Chemicals, synthetics, solvents & 8.0 \\
\hline Others & $\cdots--$ \\
\hline
\end{tabular}


of aldehydes collected. Generally, the quantities of all aldehydes produced from lipids oxidation were reduced, saturated aldehydes were also reduced by a factor of two, while the unsaturated ones reduced by a factor of at least 10 (Farmer and Mottram, 1992). Aldehydes often have very low odor threshold values and can cause rancid odors in foods. Therefore, their reduction by the presence of Maillard reactants will be of some importance for the quality of foods (Bailey et al., 1987). Also, it was suggested that, presence of amino groups somehow promotes the formation of 2-alkanones during heating (Farmer and Mottram, 1994).

Fatty acids, like long-chain alkanals, were also not substantial as flavor carriers. Hydrocarbons with $10-16$ carbon atoms were present, but they can not be considered as substances of major importance because of their higher detection threshold (Farouk et al., 2001). According to Ho et al. (1989), oxidative or thermal degradation of carotenoids leads to alkyl benzenes or terpenic derivatives, while phenolic acids degradation gives phenols.

Table (2) shows an evaluation for the browning degree in the extrudate. The increase of $a^{*}$ and $b^{*}$ corresponds to the increase in redness and yellowness, respectively, which occurs in the beginning of nonenzymatic browning. Products with more intensive green and blue color notes are formed only later, as a result of secondary reactions. Such reactions can not occur in course of very short extrusion time of 30 seconds and at relatively low temperature $120^{\circ} \mathrm{C}$ (Pokorny et al., 2002).

Sensory evaluation of the extrudate is represented in Table (3). In agreement with the volatiles detected, many aroma properties could be presented by different compounds, e.g. malty (3-methylbutanal), sweet (furans and pyrans), cocoa (2-isopropyl-5-methyl-hex2-enal), bread crumb (pyrroles), and onion - like (dimethyltrisulfide).This is generally in agreement with Bredie et al. (1998 a \& b), in spite of the different technique used.

\section{Conclusions}

From the above results it could be concluded that the nonenzymatic browning was only moderate which is clearly observed through the color parameters of the extruded maize flour, however, using SPME extraction technique for the first time in this study and GC/MS, successfully extracted and identified more than 90 compounds, many of them were not reported before. The study was performed, also for the first time, at the standard industrial conditions including temperature and normal moisture content. Sensory evaluation of the extruded sample could be easily understandable in comparison to the identified compounds and their sensory properties.

\section{REFERENCES}

Bailey M. E., Shin-Lee S. Y., Dupuy H. P., St. Angelo A. J. and Vercellotti J. R. (1987). Inhibition of warmed - over flavor by Maillard reaction products. In Wormed over flavor of meat, St. Angelo, A. J. and Bailey, M. E., Ed., Academic Press, London. 237-266.

Baltes W. and Bochmann G. (1987). Model reactions on roast aroma formation. III. Z. Lebensm. Unters. Forsch. 184: 478-484.

Bredie W. L. P., Mottram D. S. and Guy R. C. E. (1998a). Aroma volatiles generated during extrusion cooking of maize flour. J. Agric. Food Chem. 46: 1479-1487.

Bredie W. L. P., Mottram D. S., Hassell G. M. and Guy R. C. E. (1998b). Sensory characterization of the aromas generated in extruded maize and wheat flour. J. Cereal Sci. 28: 97-106.

Buttery R. G. and Ling L. C. (1995). Volatile flavor components of corn tortillas and related products. J. Agric. Food Chem. 43: 1878-1882.

Buttery R. G., Ling L. C. and Stern D. J. (1997). Studies on popcorn aroma and flavor volatiles. J. Agric. Food Chem. 45: 837843.

Camire M. E. (1998). Chemical changes during extrusion cooking. In Process - Induced Chemical Changes in Food; Shahidi, et. al., Ed., Plenum Press, New York. 109121.

Chen J., Serafin F. L., Pandya R. N. and Daun H.(1991). Effects of extrusion conditions on sensory properties of corn meal extrudates. J. Food Sci. 56: 84-89.

Farmer L. J. and Mottram D. S. (1992). Effect of cysteine and ribose on the volatile thermal degradation products of a triglyceride and three phospholipids. J. Sci. Food Agric. 60: 489-497.

Farmer L. J. and Mottram D. S. (1994). Lipid Maillard interactions in the formation of volatile aroma compounds. In Trends in Flavor Research; Maarse H. and van der Heij, D. G., Ed., Elsevier Sci. B. V., Netherlands. 313-326.

Farmer L. J., Mottram D. S. and Whitfield F. B. (1989). Volatile compounds produced in Maillard reactions involving cysteine, 
ribose and phospholipids. J. Sci. Food Agric. 49: 347-368.

Farouk M. A, Pudil F., Janda V. and Pokorny J., (2000). Effect of amino acids on the composition and properties of extruded mixtures of wheat flour and glucose. Nahrung. 44: 188-192.

Farouk M. A, Pudil F., Janda V. and Pokorny J. (2001). Changes during the extrusion of semolina in mixture with sugars. Czech $\mathrm{J}$. Food Sci.19: 24-30.

Fors S. (1983). Sensory properties of volatile Maillard reaction products and related compounds: A literature review. In Maillard reaction in Foods and Nutrition; Walker, G. R. and Feather, M. S., Ed., ACS, Washington, D. C. 185-286.

Fors S. M. and Eriksson C. E.(1986). Pyrazines in extruded malt. J. Sci. Food Agric. 37: 991-1000.

Grosch W. (1982). Lipid degradation products and flavour. In Food Flavors, Morton, I. D. and MacLeod, A. J., Ed., Elsevier, Amsterdam. 325-398.

Guth H. and Grosch W. (1993). Aroma compounds from extruded oat flour,changes during storage. Z. Lebensm. Unters. Forsch. 196: 22-28.

Ho C.T., Bruechert L. J., Kuo M. C. and Izzo M. T. (1989). Formation of volatile compounds from extruded corn - based model systems. In Thermal Genration of Aromas, Parliament T. H., McGorrin, R. J. and Ho, C.-T., Ed., ACS, Washington, D. C. 504-511.

Huber G. R. (1991). Carbohydrates in extrusion processing. Food Technol. 45: 160-161.

Hwang H. I., Hartman T. G., Karwe M. V., Izzo H.V. and Ho C. T. (1994b). Aroma generation in extruded and heated wheat flour. In Lipids in Food Flavors, Ho, C.-T. and Hartman, T. G., Ed., ACS, Washington, D. C. 144-157.

Hwang H. I., Hartman T. G., Rosen R. T., Lech J. and Ho C. T. (1994a). Formation of pyrazines from the Maillard reaction of glucose and lysine. J. Agric. Food Chem. 42: 1000-1004.

Izzo H. V. and Ho C. T. (1991). Isolation and identification of the volatile components of an extruded autolyzed yeast extract. J. Agric. Food Chem. 39: 2245-2248.

Madruga M. S. and Mottram D. S. (1998). The effect of $\mathrm{pH}$ on the formation of volatile compounds produced by heating a model system containing 5-Imp and cysteine. J. Braz. Chem. Soc. 9: 261-271.
Maga J. A. (1992). Pyrazine update. Food Rev. Int. 8: 479-558.

Maga J. A. and Sizer C. E. (1979). Pyrazine formation during the extrusion of potato flakes. Lebensm. Wiss. Technol. 12: 1516.

Mottram D. S. and Whitfield F. B. (1995). Volatile compounds from the reaction of cysteine, ribose, and phospholipids in low moisture system. J. Agric. Food Chem. 43: 984-988.

Mulders E. J. (1973). Volatile compounds from the non - enzymic browning reaction of the cysteine / cystine - ribose system. Z. Lebensm. Unters. Forsch. 152: 193-201.

Nair M., Shi Z., Karwe M. V., Ho C.-T. and Daun H. (1994). Collection and characterization of volatile compounds released at the die during twin screw extrusion of corn meal. In Thermally Generated Flavors; Parliament T. H, Morello, M. J. and McGorrin, R. J., Ed., ACS, Washington, D. C. 334-347.

Pawliszyn J. (1997). In SPME, Theory and Practice, Wiley - VCH, New York.

Pokorny J., Farouk M. A., Pudil F. and Janda V. (2002). Effect of defatted soybean flour on the flavour of extruded mixtures with wheat flour. Czech J. Food Sci. 20: 229236.

Politz M. L., Timpa J.D. and Wasserman B. P.(1994). Quantitative measurement of extrusion-induced starch fragmentation products in maize flour using nonaqueous automated gel- permeation chromatography. Cereal Chem. 71: 532536.

Riha W. E. and Ho C. T. (1998). Flavor generation during extrusion cooking. In Process - Induced Chemical Changes in Food, Shahidi, et al.,Ed., Plenum Press, New York. 297-306.

Schieberle P. (1991). Primary odorants of popcorn. J. Agric. Food Chem. 39: 11411144.

Shibamoto T. (1977). Formation of sulfur- and nitrogen - containing compounds from the reaction of furfural with hydrogen sulfide and ammonia. J. Agric. Food Chem. 25: 206-208.

Shibamoto T. (1980). Heterocyclic compounds found in cooked meats.J. Agric. Food Chem. 28: 237-243.

Shu C. K., Hagedorn M. L., Mookherjee B. D. and Ho C. T. (1985). Volatile components of the thermal degradation of cysteine in water. J. Agric. Food Chem. 33: 438-442. 
Sizer C. E., Maga J. A. and Lorenz K. (1975). The occurrence of pyrazines in white bread crust and crumb. Lebensm.- Wiss. Technol. 8: 267-269.

Yaylayan V. A., Fichtali J. and van de Voort F. R.(1992).Production of Maillard reaction flavour precursors by extrusion processing. Food Res. Int. 25: 175-180.
Zhang J.(1994). Chemistry and protein deamidation: reaction kinetics, parameter effects and impact on flavor generation. Dissert. Abstr. Int. B., 54, 5457.

Zhang Y., Chien M. and Ho C.-T. (1988). Comparison of the volatile compounds obtained from thermal degradation of cysteine and glutathione in water. J. Agric. Food Chem. 36: 992-996.

\section{تحليل المركبات الطيارة الناتجة عن بثق دقيق الذرة باستخدام جهاز الإستخلاص الدقيق \\ ذو المادة الجاذبة الصلبة (SPME)}

$$
\text { قسم كيمياء مكسبات الطعم و الر ائحة ــ المركز القومى للبحوثــ الدقى ــ الجيزة ـمصر }
$$

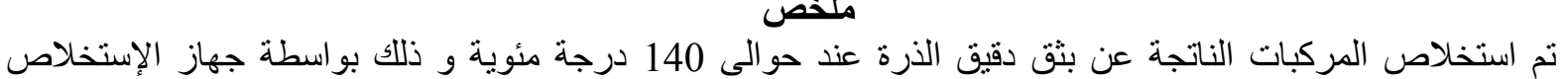

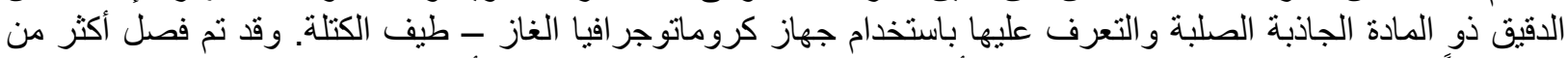

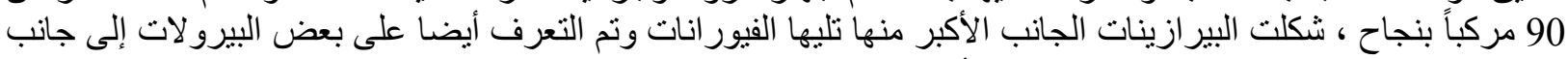

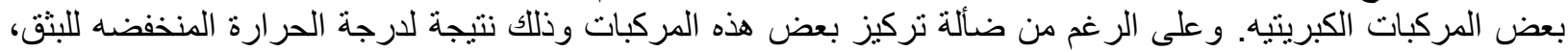

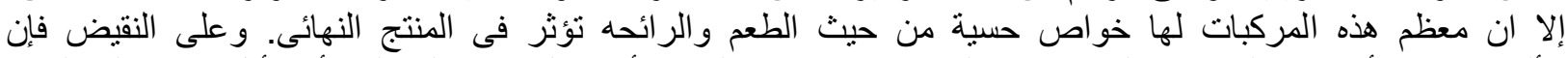

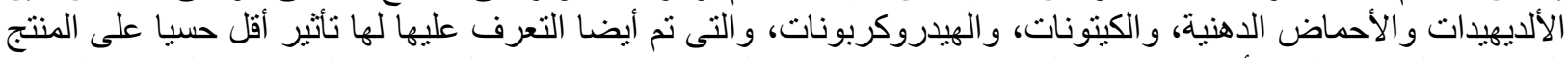

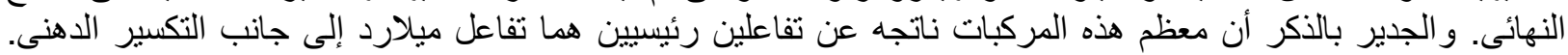

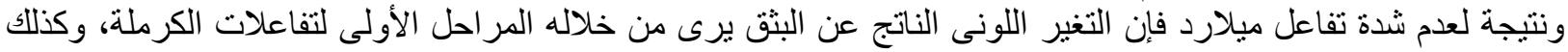

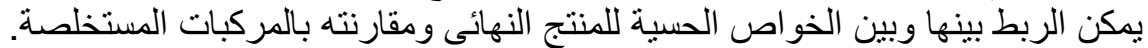

